\title{
Recovery after stroke
}

\author{
CLIVE E SKILBECK, DERICK T WADE, R LANGTON HEWER, \\ VICTORINE A WOOD
}

\author{
From the Stroke Recovery Research Unit, Department of Neurology, Frenchay Hospital, Bristol, UK
}

SUMMARY One hundred and sixty-two patients were referred to a rehabilitation unit after an acute stroke. The patterns of recovery of overall functional ability, arm function, walking and speech in 92 of 101 survivors have been analysed. In all modalities the majority of recovery occurs within 3 months; although improvement is seen thereafter it does not reach statistical significance. Possible reasons for the apparent lack of late recovery are discussed.

Most patients who have suffered an acute stroke improve considerably over the succeeding months. The precise reasons for this are unknown, although various mechanisms have been suggested. ${ }^{1}$ Even the natural history of recovery, its speed, duration and final extent are still not accurately known. Most reports ${ }^{2-5}$ agree that the majority of recovery occurs within the first 3 to 6 months, but there is some disagreement over the importance and extent of later improvement, with studies on selected patients ${ }^{56}$ demonstrating appreciable late recovery.

This paper presents data relating to the speed, duration and final extent of recovery. We have measured the recovery of four functions (speech, walking, the functional use of the arm and overall physical ability) in a large group of patients selected only by the fact of being referred to a stroke rehabilitation unit within an ordinary district general hospital.

\section{Patients and methods}

The patients in this study were the 162 acute strokes referred to the Frenchay Stroke Unit, a specialist rehabilitation department, over the 2 years 1 September 1976-31 August 1978. All stroke patients referred were accepted provided that they lived locally and were fit enough to be examined. There were equal numbers of men and women, of whom 81 were right hemiplegics, 73 were left hemiplegics and eight had non-hemiplegic strokes (for example dysphasic, brain stem stroke). The mean age was 67.5 years (SD $9 \cdot 4$, range 36-89 years). Forty-four were never admitted to hospital and received all their therapy as out-patients.

Patients were seen as soon as possible after their stroke.

Address for reprint requests: Dr R Langton Hewer, Department of Neurology, Frenchay Hospital, Bristol, BS16 ILE, UK.

Received 11 June 1982, and in revised form 10 September 1982.

Accepted 30 September 1982
Thirty-four were seen in the first week, 61 in the second week, 31 in the third week, 11 in the fourth week, eight in the fifth week, 12 between weeks 6-9, and five thereafter. The median interval was 12 days and the range 2-86 days. Patients were then seen at $1,3,6,12$ and 18 months and finally at 2 or 3 years after the stroke. These assessments were done whether or not the patient was still under active treatment, but because they were carried out by the therapists as part of their normal work, some patients did not receive all their assessments.

Of the 162 patients referred and given an initial assessment, 101 survived to final assessment ( 59 at 2 years and 42 at 3 years), but nine could not be seen, usually because the patient had left the area. This left 92 patients, who will be called the "survivors".

Information was collected on standard forms with guidance notes. No specific training was given in most of the assessments (except that for speech). The following parameters were measured:

Overall function Functional ability was measured using the Barthel Activities of Daily Living (ADL) scale. This scale was developed ${ }^{7}$ in the United States; it is empirically based but has been validated ${ }^{8}$ and used in other studies on stroke. ${ }^{910}$ The patient's ability to perform ten separate functions is assessed, a score given for each, and the total recorded. The scale ranges from $0-100$, having increments of 5 points, and the items are shown in table 1 :

It must be stressed that a score of 100 does not necessarily imply normality, but only that the patient should manage without attendant care. He may still need other help (for example to cook, to go shopping).

Speech Speech function was assessed using the Functional Communication Profile (FCP), a standardised method ${ }^{11}$ of measuring the patient's ability to communicate both verbally and non-verbally. It was administered by therapists specially trained in its use. The score ranges from $0-100$.

Arm function The functional ability of the affected arm was measured using seven graded tasks: (1) Use both hands to open jam jar, (2) Use both hands to rule a line, (3) Use affected hand to pick up and release $5 \mathrm{~cm}$ cylinder, (4) Use affected hand to pick up and release $1.25 \mathrm{~cm}$ cylinder, (5) Use affected hand to drink water from glass, (6) Use affected hand to comb hair, (7) Use affected hand to open and close clothes peg. This gives a $0-7$ scale. 
Table 1 Criteria for Barthel Index

\begin{tabular}{lrl}
\hline Index item & Score weight $^{*}$ & Description \\
\hline Feeding & 10 & Independent \\
& 5 & Needs help \\
Bathing & 5 & Performs without assistance \\
Personal toilet & 5 & Washes face, combs hair, \\
(grooming) & & brushes teeth, shaves \\
Dressing & 10 & Independent \\
& 5 & Needs help \\
Bowel control & 10 & No accidents \\
& 5 & Occasional accidents \\
Bladder control & 10 & No accidents \\
& 5 & Occasional accidents \\
Toilet & 10 & Independent \\
& 5 & Needs help \\
Chair/bed transfers & 15 & Independent \\
& 10 & Minimum assistance \\
& 5 & Able to sit but needs \\
& & maximum assistance to \\
& & transfer \\
& Independent for $45 \mathrm{~m}$ \\
Ambulation & 15 & With help for $45 \mathrm{~m}$ \\
& 10 & Wheelchair for $45 \mathrm{~m}$ \\
Independent
\end{tabular}

${ }^{*} 0$ is scored if unable to perform task.

Mobility Mobility is included in the Barthel scale, but it has been analysed separately because it is of such practical importance. Patients were divided into three groups: "independent" (with or without walking aid, but does not need help), "partially dependent" (needs help of one person), "dependent" (unable to function without help of more than one person).

\section{Results}

The tests all give ordinal scales, and the distribution of scores was usually heavily skewed. Therefore, the graphs are all based upon median scores. The $t$ test has been used to assess the statistical significance of any differences unless otherwise stated.

\section{Overall function}

The 92 survivors were sub-divided into three groups according to their initial disability, as judged by their Barthel score. The graph (fig 1) illustrates the

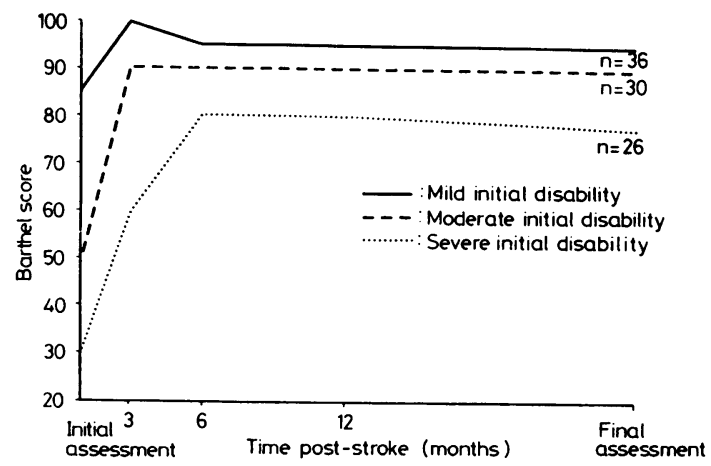

Fig 1 Median Barthel scores for survivors in 3 groups. recovery curves for the three groups. The severely disabled (Barthel score $\leqslant 40, n=26$ ) show a considerable improvement over the first 3 months ( $\mathrm{p}<0.001$ ) and continuing (but statistically nonsignificant) improvement up to 6 months. The moderately disabled (Barthel score $41-60, n=30$ ) improved over the first 3 months $(p<0.001)$, as did the mildly disabled (Barthel $61+, n=36, p<0.01$ ), but neither showed further improvement after 3 months.

\section{Speech}

Thirty-eight patients of the initial 162 had an initial FCP score of 85 or less, indicating an appreciable disturbance of speech function. Thirty-five had an associated right hemiplegia, two a left hemiplegia and one had isolated dysphasia. Seventeen of these 38 survived (including the two left hemiplegics and the one isolated dysphasia), and the graph (fig 2) shows the recovery in the median FCP score for this small group. Again, it can be seen that the majority of recovery occurs within 3 months $(p<0.05)$ and, although there is a continuing upward trend, this did not achieve statistical significance.

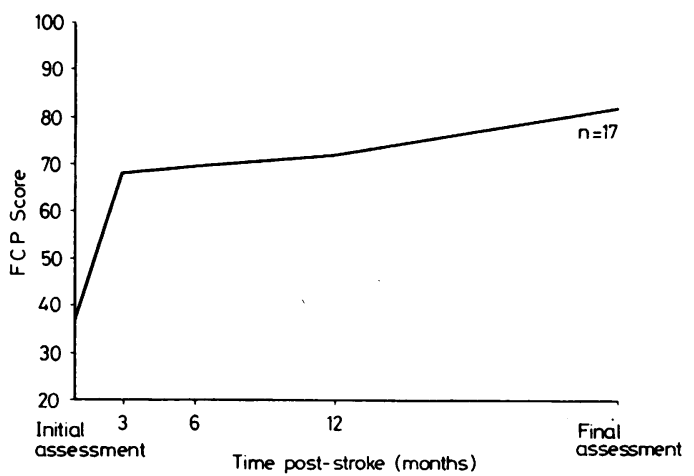

Fig 2 Language recovery: median FCP scores.

\section{Arm function}

The third graph (fig 3) plots the median arm function score against time. Again there is clearly rapid initial recovery with a continuing trend upward until one year after the stroke. To assess the significance of any improvement we have used the Wilcoxon signed-rank paired-differences test which allows one to compare the scores of individual patients on two separate occasions: this was particularly important as only 55 patients were assessed on every occasion. Using this method we found a highly significant improvement between 3 weeks and 3 months $(p<0.0001)$ and a less significant improvement for the 6-12 month comparison ( $p<0.05$, one tailed). Comparison between other time points did not show statistically significant improvement. 


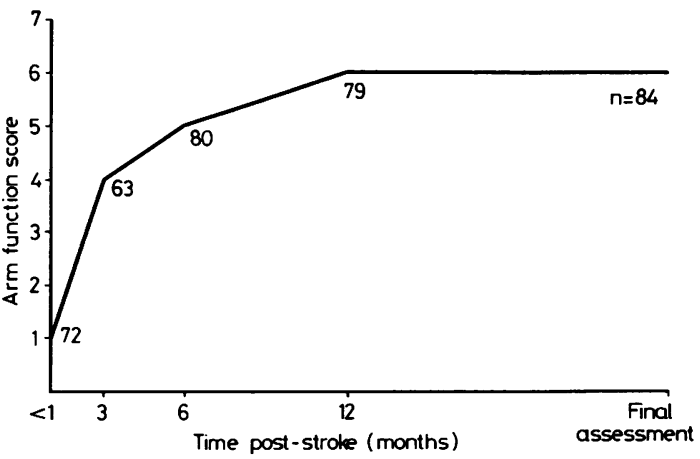

Fig 3 Median Arm Function scores for survivors.

The pass rates for three individual tests is shown in the final graph (fig 4). The tests chosen are an easy one (number 1), a moderate one (number 4) and a difficult one (number 6). This graph illustrates a late improvement in the most difficult test. It is not statistically significant, but is discussed later.

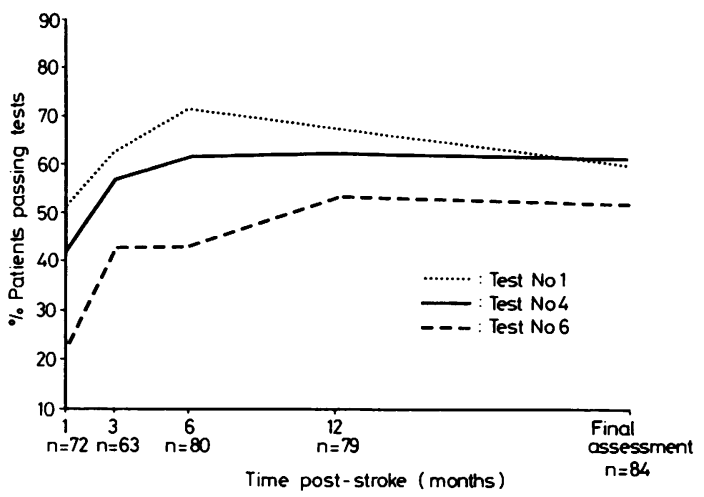

Fig 4 Pass Rate for 3 Arm Tests against Time.

\section{Walking}

Table 2 documents walking ability at the various follow-up points. The rapid early improvement is apparent but the little change that occurs after 6 months does not reach statistical significance.

\section{Discussion}

The most obvious feature of these results is the demonstration of an early rapid phase of recovery within the first 3 months. This occurred in all modalities, both specific (that is speech, arm function) and more general (that is ADL ability, walking). This finding is in agreement with clinical experience and has been documented previously. ${ }^{2-5} 12$ The final extent of recovery in our series is also in agreement with this previous work.

The most interesting question that has yet to be resolved is whether or not there is any recovery after 6 months. Clearly individual patients do improve. Andrews et $a l^{2}$ found that $6.5 \%$ of 1 year survivors had shown some improvement between 6 months and 1 year, and Katz et al ${ }^{4}$ similarly identified a few individual patients who improved up to 2 years after the stroke. In a very selected group of patients Bard and Hirschbergs documented late improvement in arm function in four out of 16 patients followed up for 1 year. However, variability in performance is often seen after stroke 5 and it has not been shown conclusively that the recovery process continues beyond 6 months after the stroke. It may be that there is no general recovery after this time, but there are several other reasons why it may not have been found. The most likely is that the measuring instruments are at fault, being too insensitive in the upper range leading to a "ceiling effect". In the Barthel score, for example, over $50 \%$ of patients have achieved a score of 95 or more by 6 months; thus, there is little chance of detecting further improvement. The possibility of a ceiling effect in the Barthel score is supported by the trends upward shown in both the recovery of speech and the recovery of arm function. Furthermore, the severely disabled show considerable improvement in Barthel score between 3 and 6 months, while the rest show no measurable improvement. Again, in fig 4 it can be seen that the most difficult test (which is sensitive in the upper range of ability) shows its greatest improvement after 6 months. In the context of recovery of function after head injury 13 it has been shown that low-level tests returned to normal well before more complex ones.

It is also possible that patients are not receiving enough therapy or are not receiving it at the correct time. In the 92 survivors we could only find three who improved by 10 or more points in their Barthel score after 6 months. One of these had had a deterioration between 3 and 6 months, due to an acute arthritis. The other two, however, showed a definite

Table 2 Walking status

\begin{tabular}{llllr}
\hline Time after-stroke & Total & Independent & Partially dependent & Dependent \\
\hline Initial & 101 & $30(30 \%)$ & $29(29 \%)$ & $42(42 \%)$ \\
3 Months & 90 & $64(71 \%)$ & $18(20 \%)$ & $8 \%)$ \\
6Months & 90 & $73(81 \%)$ & $12(13 \%)$ & $6 \%)$ \\
12 Months & 91 & $76(84 \%)$ & $9(10 \%)$ & $6(7 \%)$ \\
Final & 92 & $76(83 \%)$ & $6(7 \%)$ & $10(11 \%)$ \\
\hline
\end{tabular}


continuation of previous improvement, and in both these cases improvement was associated with a second period of therapy. The recent study from Northwick Park Hospital 14 has shown that therapy itself is probably of benefit. A large North American study ${ }^{6}$ has shown that rehabilitation given at 6 months or even 1 year after an acute stroke could still lead to a measurable, worthwhile improvement. A recent study on speech therapy 15 showed that patients who had had no therapy until at least 3 months after the stroke nevertheless made a rapid improvement once given therapy.

A third possibility is that any neurophysiological or adaptive recovery is counterbalanced by a gradual deterioration in function associated with ageing and other diseases, leading to an apparently static level of function. Certainly in head injured patients, ${ }^{13} 16$ who are decades younger, there is evidence of prolonged recovery.

In conclusion, it is likely that neurophysiological recovery may continue for years following some forms of acquired brain damage. ${ }^{13}$ However, in the aged and ageing population of stroke patients, the lack of sensitivity of the tests combined with the normal variability of performance makes it difficult to detect this recovery after the first 3 months.

\section{References}

${ }^{1}$ Bach-y-Rita P. Central Nervous System Lesions: Sprouting and Unmasking in Rehabilitation. Arch Phys Med Rehabil 1981;62:413-7.

2 Andrews K, Brocklehurst JC, Richards B, Laycock PJ. The rate of recovery from stroke and its measurement. Int Rehab Med 1981;3:155-61.
3 Carrol D. The disability in hemiplegia caused by cerebrovascular disease. J Chron Dis 1962;15:179-89.

${ }^{4}$ Katz S, Ford AB, Chinn AB, Newill VA. Prognosis after strokes. Part II: Long term course of 159 patients. Medicine (Balt) 1966;45:236-46.

5 Bard G., Hirschberg GG. Recovery of Voluntary Motion in the upper extremity following hemiplegia. Arch Phys Med Rehabil 1965;46:567-72.

${ }^{6}$ Lehmann JF, De Lateur BJ, Fowler RS et al. Stroke: does rehabilitation affect outcome? Arch Phys Med Rehabil 1975;56:375-82.

7 Mahoney FI, Barthel DW. Functional evaluation: The Barthel Index. Maryland State Med J 1965;14:61-5.

8 Wylie CM. Measuring end results of rehabilitation of patients with stroke. Pub Health Reports (USA) 1967;82:893-8.

9 Granger CV, Sherwood CC, Greer DS. Functional status measures in a comprehensive stroke case program. Arch Phys Med Rehabil 1977;58:555-61.

10 Granger CV, Dewis CS, Peters NC, Sherwood CC, Barrett JE. Stroke Rehabilitation: Analysis of repeated Barthel Index Measures. Arch Phys Med Rehabil 1979;60:14-7.

1 Sarno MT. The functional communication profile: manual of directions. Rehabilitation Monograph 42. New York: Institute of Rehabilitation Medicine, 1969.

12 Kinsella G, Ford B. Acute recovery patterns in stroke patients. Med J Aust 1980;2:663-6.

13 Van Zomeren AH, Deelman BG. Long-term recovery of visual reaction time after closed head injury. $J$ Neurol Neurosurg Psychiatry 1978;41:452-7.

14 Smith DS, Goldenberg E, Ashburn A, et al. Remedial Therapy after stroke: a randomised controlled trial. $\mathrm{Br}$ Med J 1981;282:517-20.

15 David R, Enderby P, Bainton D. Treatment of acquired aphasia: speech therapists and volunteers compared. $J$ Neurol Neurosurg Psychiatry 1982;45:957-61.

16 Roberts AH. Severe accidental head injury. An assessment of long-term prognosis London. Macmillan Press, 1979. 